\title{
A formação do psicólogo e as áreas emergentes
}

Ao lado das áreas "tradicionais", começam a configurar-se "áreas emergentes" no mercado de trabalho. Entretanto, a graduação objetiva a formação de generalista. $O$ artigo analisa o problema e apresenta propostas para sua discussāo.

\author{
Maria Teresa de Melo Carvalho \\ Jáder dos Reis Sampaio \\ (Universidade Federal de Minas Gerais)
}

\section{Áreas emergentes na atuação do psicólogo}

É conhecido por toda a categoria dos psicólogos que a lei 4119 de agosto de 1962 dispõe sobre os cursos de formação em psicologia e regulamenta a profissão. Ela determina funções privativas do psicólogo e, entre outras, a tríade de títulos que o profissional graduado pode obter: o bacharelado, a licenciatura e o título de psicólogo. O espírito da lei volta-se à formação generalista, à medida que habilita o profissional psicólogo a atuar em qualquer área da Psicologia.

Vinte e três anos após a regulamentação, o Conselho Federal de Psicologia elaborou um documento para integrar o Catálogo Brasileiro de Ocupaçōes do Ministério do Trabalho, onde se identificam as seguintes áreas de atuacão: Psicólogo Clínico (onde já se vêem descrições de atividades típicas do que se vem denominando Psicologia Hospitalar ou Psicologia da Saúde), Psicólogo do Trabalho (e não mais portanto psicólogo industrial ou industrialista), Psicólogo do Trânsito, Psicólogo Educacional, Psicólogo Jurídico (ainda sem as atividades típicas do que se está denominando Psicologia Militar), Psicólogo do Esporte, Psicólogo Social e Professor de Psicologia (nível de segundo grau e nível superior). Uma leitura detida nas atribuições destes muitos profissionais com uma mesma habilitação leva-nos a concluir, sem medo, que a prática da
Psicologia vem consolidando-se e ampliando-se em nossa sociedade com o passar das décadas. Ao lado das áreas de atuação do psicólogo que podemos chamar de "tradicionais", quais sejam, a clínica, a escolar, a do trabalho e a social, começam a configurar-se "áreas emergentes" no mercado de trabaIho.

Ora, a emergência de uma nova área de atuaçāo do psicólogo (e, vale dizer, de qualquer outro profissional) depende em grande parte do trabalho de pioneiros. Ou seja, é na medida em que psicólogos, solicitados a desenvolver determinada atividade, mostram competência nesta atividade, e mesmo a sua viabilidade, é que se abrem possibilidades a novos colegas. Estas possibilidades ampliam-se no movimento de vaivém entre oferta e demanda, típico do mercado de trabalho.

No crescendo dessa demanda é que surgem, em geral, as inquietaçōes sobre a formação do profissional que deverá atuar nesta área. Algumas perguntas novas começam a repetir-se cada vez mais insistentemente. A qualificação percebida pelo psicólogo nos cursos de graduaçāo realmente lhe confere uma base sólida para o exercício de qualquer uma destas áreas? Uma vez graduado o recém-psicólogo pode aceitar o encargo de psicólogo do esporte, por exemplo, em um grande (ou pequeno, que seja) time de futebol? Ele dispõe de um rol de conhecimentos e técnicas que lhe permite realizar minimamente seu encargo, enquanto procura 
por cursos de pós-graduação que the possibilitem uma especialização? As interrogaçōes multiplicam-se e detêmse, em geral, nos currículos. De que forma esta área emergente relacionase com as demais disciplinas ? Cabe propor uma mudança curricular de forma a incluir novas disciplinas? Ou seria esta nova área deixada a cargo de cursos de especialização? Como contemplar tal área nos estágios?

Sem pretender propor respostas a tais questōes, faremos em seguida algumas consideraçōes que, muito mais do que indicar caminhos, tem por objetivo suscitar reflexōes.

\section{Áreas emergentes e reformas curriculares}

Os currículos plenos dos cursos de Psicologia foram, de um modo geral, elaborados visando à formação do psicólogo "generalista", seguindo aí o espírito da lei que regulamentou a profissão. Isto é, os cursos privilegiam o conhecimento genérico em temas psicológicos, proporcionando uma formação científico-metodológica e o desenvolvimento de habilidades técnicas que serão úteis nas intervenções do psicólogo em geral, sem a delimitação de áreas de atuação específicas. Sabemos, no entanto, que embora não sendo voltados para a formação específica, os cursos de Psicologia organizam-se segundo elencos de disciplinas que vêm a configurar as áreas de atuação do psicólogo que, até então, têm sido as principais: clínica, trabalho, escolar e social.

Em análise realizada por Bastos \& Gomide dos resultados da pesquisa feita pelo CFP entre 1986 e 87 , visando obter o perfil do psicólogo brasileiro, estes autores constataram, no que diz respeito à formaçāo profissional, um alto grau de insatisfação (mais de $50 \%$ da amostra) com a fundamentação fiIosófica, metodológica e científica adquirida na graduação. Esta insatisfação é ainda maior quando se refere à ex-

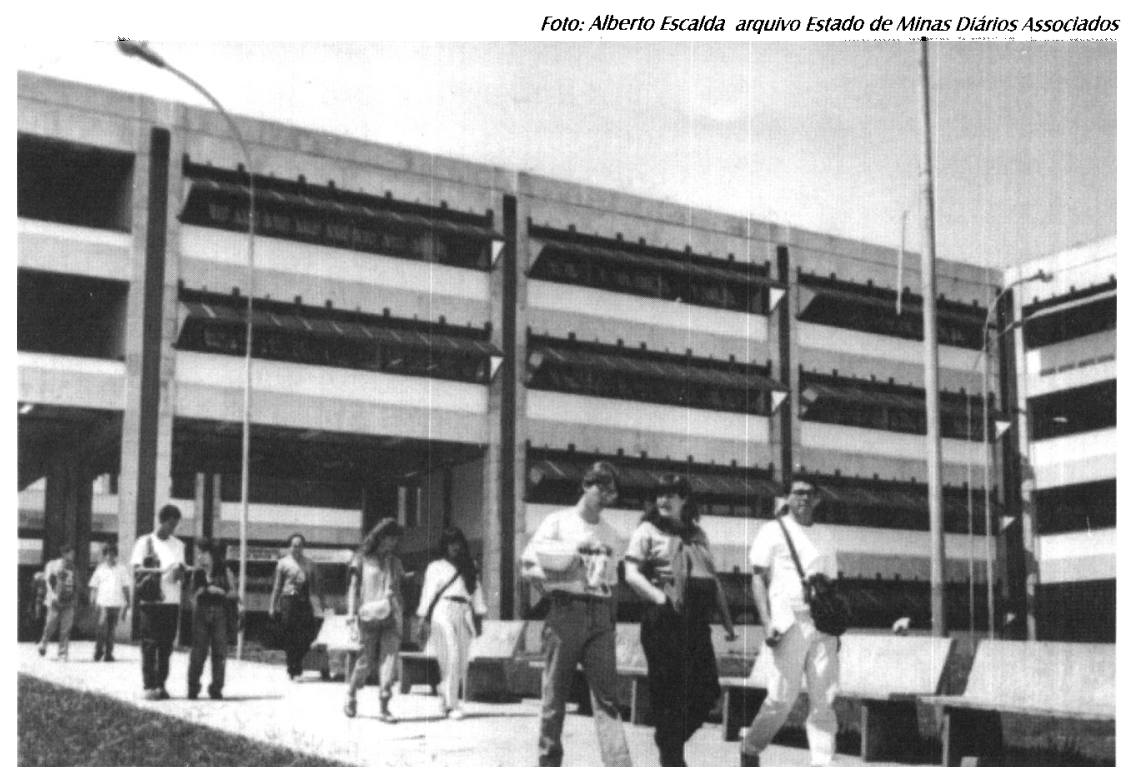

periência científica. Com relação aos conhecimentos mais diretamente ligados a uma determinada área de atuação profissional, o índice de insatisfação decresce, principalmente na prática da psicologia clínica, aumentando um pouco nas áreas escolar e organizacional ou do trabalho. Ou seja, a satisfação dos ex-alunos com os conhecimentos referentes a atuaçōes específicas é maior do que com os conhecimentos mais genéricos e fundamentais, sobretudo aqueles ligados à fundamentação científico-metodológica. Nesta análise, é interessante notar também que, com o passar dos anos, essa defasagem aumentou, isto é, relativamente aos colegas formados anteriormente, os psicólogos formados a partir dos anos 80 avaliaram mais positivamente os conhecimentos voltados para a prática clínica e escolar e mais negativamente a fundamentação filosófica, científica e metodológica (Bastos \& Gomide, 1989: 13).

Nos resultados desta pesquisa as "áreas emergentes", relacionadas no documento do CFP, ainda não são mencionadas, estando certamente incluídas na categoria "outras". A concentração de psicólogos por área de atuação apresenta variaçōes segundo as regiōes, mas em todas elas prevalece a área clínica. $O$ que evidentemente é de se esperar à medida que a representação social da Psicologia se cons- 
titui em torno da imagem da Psicologia Clínica, que por sua vez, se acha melhor constituída dentro das instituiçōes de ensino. Desta forma, a maioria dos alunos de Psicologia acaba sendo atraída pela formação clínica, seja a psicoterapia "de consultório", especificamente, sejam os seus desdobramentos, como a Psicologia Hospitalar, a saúde mental no trabalho, entre outros. Consideramos, por todos estes motivos, que a clínica ainda é o grande aglutinador das diferentes áreas de atuação do psicólogo.

Mas neste ponto voltamos às nossas interrogaçōes iniciais: a constatação de áreas emergentes no mercado de trabalho deveria refletir imediatamente em reformas curriculares, de tal forma que fossem incluídas novas disciplinas, ligadas a essas áreas? Seria esta a medida mais adequada para fazer face às novas demandas? Responder sim a esta interrogação seria talvez a nossa tendência mais espontânea, mas não restam dúvidas de que é a opção mais simplista e que logo esbarraria em outros problemas. Problemas mais fundamentais ligados, por um lado, ao currículo e, por outro, às possibilidades de implementação deste currículo.

Uma reforma curricular que visaria, entre outras coisas, fazer face às demandas crescentes em novas áreas de atuação, não poderia deixar de considerar esta insatisfação com a formação básica. Embora não disponhamos de dados de pesquisas mais recentes, acreditamos, baseados em nossa convivência com psicólogos recém-formados e alunos dos últimos anos de Psicologia, que a carência de uma formação básica mais sólida, incluindo aí a experiência científico-metodológica, ainda persiste e quiçá tem aumentado nos psicólogos formados na década de 90. Assim, concordamos com os autores acima citados quando afirmam que o aprimoramento da formação não depende simplesmente de um acréscimo de conteúdos nos cursos, mas da estruturação destes segundo uma "política" de formação que privilegie a participaçāo dos es- tudantes no próprio processo de construção do conhecimento. Ao insistirmos aqui na formação básica não estamos pensando apenas em currículo mínimo ou em disciplinas que constituiriam, por assim dizer, o "ciclo básico" da Psicologia por oposição ao "ciclo profissionalizante", mas em uma formação científica que deve estar presente ao longo de todo o curso. Como afirmam Bastos \& Gomide, apoiados em um trabaIho de Weber (1985): no que se refere à formaçāo científica, não se trata de introduzir ou redefinir disciplinas e/ou matérias no currículo mínimo que venham a favorecer tal formação, mas repensar a estruturacão do curso de Psicologia "de tal forma que se permitisse ao estudante a sua participação em um processo de construção do conhecimento em realizaçāo, no Departamento em que está inscrito" (Bastos \& Gomide, 1989: 12).

Um outro trabalho de pesquisa sobre a formação do psicólogo, realizado com alunos de graduação do IPUSP por $A$. $M$. de Almeida Carvalho, chega a conclusões semelhantes às dos autores acima, ou seja, constata a necessidade de melhorar o aspecto da formação que diz respeito à pesquisa. Esta autora argumenta ainda que "através de uma boa formação em pesquisa, podemos formar um profissional que vai atuar em qualquer área, com uma atitude de pesquisador" (Carvalho, 1989: 21). Esta atitude de pesquisador capacita o profissional a "criticar, analisar, reformular, inventar, pensar" a situação co'n que se defronta e não se restringi: à posição de um técnico "aplicador de procedimentos aprendidos".

A preocupação com a formação básica é pois um ponto fundamental, mas ainda assim não podemos nos furtar da confrontação com a formação profissional, onde o tema das áreas emergentes volta ao primeiro plano. Simplesmente acrescentando conteúdos, correríamos o risco de fazer mudanças de "forma pontual e pouco coerente" que vem dando uma "formaçāo em generalidades", como bem observou Lo Bianco (1996: 20). A inclusão de disciplinas com conteúdos específicos das novas 
áreas não seria, então, um ponto de partida, mas poderia ser a conseqüência de um processo ou um ponto de chegada. Esse processo deveria considerar, além da mudança curricular em si, as possibilidades de sua implementação. Essas mudanças representam, sim, possibilidades transformadoras que esbarram, entretanto, com uma série de outros problemas importantes. Mencionamos alguns exemplos:

a) A legislação atual impõe conteúdos mínimos e dispõe que o profissional psicólogo seja generalista. Alguns cursos reestruturam seus currículos de forma a obrigar seus alunos a optarem por uma área de atuação ao final do curso. Esta medida contraria a habilitação que lhes é concedida e deixa lacunas importantes no profissional formado por este programa. $O$ aluno que optasse por direcionar seu curso para a clínica, após formar-se, poderia ser convidado por uma organização a exercer atividades próprias da Psicologia do Trabalho e o diploma de psicólogo o habilita para tal. Por um motivo qualquer ele poderia aceitar a proposta (como habitualmente vemos acontecer) e desempenharia as suas atividades sem conhecimentos mínimos para tal.

b) Os atores envolvidos nas reformas intra-acadêmicas são os próprios docentes, o que introduz as questões de poder nas discussões. Ainda que tecnicamente se constate uma área emergente, politicamente se questiona que disciplinas ou conjunto de disciplinas deverão ser abandonadas para a implantação de novas áreas.

c) As áreas emergentes são constituídas a partir de práticas que transcendem a própria Psicologia, definindo-se assim na interdisciplinaridade, o que hoje constitui um desafio, não só para a Psicologia, mas para as áreas de conhecimento em geral.

d) A mera criação de disciplinas e ementas que compreendem as áreas emergentes não assegura que o ensino ministrado Ihes fará justiça. É neces- sário que, no corpo docente, haja profissionais com formação e experiência (boa vontade não é suficiente) para fazerem cumprir o planejado.

A partir destas consideraçōes, percebe-se que, embora as reformas curriculares possam ser vistas como a "instância salvadora" da formação do psicólogo, elas não resolvem, isoladamente, a complexidade dos problemas aí envolvidos.

\section{As áreas emergentes entre a graduação e a especialização}

Enquanto as escolas de Psicologia oferecem timidamente cursos de pós-graduação "lato sensu" (atualização, aperfeiçoamento e especialização) nas áreas emergentes, multiplicam-se as ofertas de cursos de curta duração por iniciativa de grupos de profissionais, sem qualquer vínculo com instituiçōes de ensino.

Isto certamente sinaliza a existência de uma demanda, por parte dos psicólogos formados, de conhecimentos específicos nestas áreas.

Considerando que houve um crescimento marcado da Psicologia nos últimos trinta e cinco anos (desde a sua regulamentação como profissão), e tendo em vista os problemas levantados anteriormente, vemos que as reformas curriculares não são suficientes para formar um profissional generalista capaz de exercer todas as atividades descritas nas diversas áreas de atuação.

Com base nesta percepção, torna-se importante discutir-se a regulamentação e promoção da especialização em Psicologia. Este, que certamente é um trabalho polêmico, envolveria a discussão em torno de ações possiveis. Enumeramos algumas a seguir.

a) Melhor delimitação das atividades que se espera que o psicólogo generalista esteja habilitado a exercer.

b) Regulamentação da especialização em Psicologia, condicionando a habilitação para o exercício de algumas dessas áreas emergentes à pós-graduação "lato-sensu". 
c) Promoção de fóruns de discussão para a revisão das disciplinas do curso de formação de psicólogo e de sua carga horária.

d) Revisão do sistema bacharelado-psicólogo (regulamentado na legislaçāo de 1962), na tentativa de modificar a relação hoje existente entre disciplinas de base $e$ disciplinas voltadas para a formação técnico-profissional. Atualmente, consideramos haver uma compressão indesejável das disciplinas do "ciclo profissionalizante" nos últimos períodos do curso, bem como uma cisão entre estas e as disciplinas de base. É comum o aluno estudar um determinado tema no início do curso sem conseguir articulá-lo à sua futura atuação como psicólogo, perdendo-o de vista no momento em que chega às disciplinas de conteúdo profissionalizante.

Alguns críticos da idéia da regulamentação da especialização argumentam que este dispositivo criaria "mercados cativos" para um pequeno grupo de psicólogos, excluindo outros. Consideramos, no entanto, que não se consegue formar na graduação um profissional ao mesmo tempo generalista e especialista em todas as áreas. Devemos ter em vista que a atuação do psicólogo nas áreas emergentes envolve também uma apreciação por parte da sociedade, que forma opiniāo sobre a Psicologia como um todo a partir das experiências particulares. Um profissional, exercendo funçōes para as quais não foi preparado, contribui para o descrédito da Psicologia em geral.

Abordaremos a seguir a questão dos estágios em áreas emergentes, o que nos possibilitará retomar, sob um novo ângulo, a relação entre estas e os cursos de formaçāo.

\section{Estágios em áreas emergentes}

Os estágios extra-curriculares, ou mesmo os curriculares, buscados fora dos departamentos por muitos estudantes que desejam complementar a sua formação, bem como experimentar a realidade do mercado de trabalho, representam um canal importante de diálogo com os próprios cursos onde estão inscritos estes estudantes. São esses es- tágios que muitas vezes despertam a atenção dos docentes para uma área emergente. Tomemos como exemplo o estágio em psicologia hospitalar, que vem sendo realizado por alunos do curso de Psicologia da UFMG. Antes mesmo que esse curso oferecesse estágios nesta área específica, fomos solicitados a fazer a seleção dos nossos alunos que apresentavam-se como candidatos para um estágio extra-curricular em um hospital de Belo Horizonte. Esta solicitação repetiu-se por dois ou três semestres consecutivos e foi um dos fatores que mobilizou professores deste curso, já interessados nesta área e nela trabalhando de forma mais ou menos marginal, a criarem um estágio curricular na referida "especialidade", no próprio espaço aberto pelo hospital da UFMG que, por seu lado, já vinha demandando estagiários de psicologia em suas equipes de atendimento ao paciente. Paralelamente à oferta desta nova modalidade de estágio, a "teoria" ligada à psicologia hospitalar vem sendo trabalhada em uma disciplina optativa cuja ementa possibilita este conteúdo. Não pretendemos afirmar que, com isso, abriu-se neste curso a possibilidade de formação em uma área emergente - a psicologia hospitalar- ; o que acabamos de relatar não é mais do que um passo incipiente nesta direção. Nem tampouco temos um modelo ideal de currículo, mas pensamos que este exemplo ilustra a participação do estudante no processo de construção do conhecimento em seu curso. $O$ aluno que busca um estágio fora dos muros das universidades ou faculdades, volta com questões que o desafiam em sua prática e que muitas vezes são o ponto de partida para um projeto de pesquisa ou para a abertura de um espaço onde estas questões possam ser trabalhadas.

Ora, a situação acima descrita contraria, de alguma forma, o princípio segundo o qual os estágios são sustentados por uma formação teórica anterior ou pelo menos paralela. Mas como seguir este princípio no caso destas novas áreas onde a prática "corre na frente" da reflexão teórica? Tomemos novamente o exemplo da psicologia hospitalar, que tem nos impressionado pelo seu crescimento acelerado em nosso meio. A entrada do psicólogo 
nos hospitais ocorreu antes que os cursos de Psicologia pudessem prevê-la e antes mesmo da regulamentação da profissão. Tratava-se, na época, de experiências isoladas, insuficientes para constituir uma identidade própria desta área. Podemos então dizer que, antes de ser um "especialista em psicologia hospitalar", o psicólogo entrou nos hospitais e de seu envolvimento com uma atividade específica, ali desenvolvida, vem se delimitando e se consolidando uma área de atuaçào.

Em sua prática, mesmo fora dos hospitais, e em suas teorias, o psicólogo está acostumado a trabalhar com o adoecer, com os impactos de uma doença orgânica sobre o estado emocional das pessoas; com o tema da morte; com pacientes portadores de doenças incuráveis, às vezes em fase terminal; com pessoas em processo de luto pela morte de um ente querido; com crianças que devem ser preparadas para uma cirurgia ou para um procedimento médico invasivo; com pessoas recém-saídas de uma cirurgia mutiladora e assim por diante... Assim, muitos dos desafios com os quais se depara o psicólogo nos hospitais não estavam, até então, ausentes de sua prática clínica nem de suas teorizacões. Pensamos, no entanto, que dentro de um hospital as questōes acima mencionadas, dentre outras, ganham relevo e passam para o primeiro plano. Passam a constituir o foco obrigatório daquele que optou por uma prática hospitalar. Queremos com isso salientar que existe um recorte nos temas da Psicologia apto a constituir uma base teórica para a psicologia hospitalar e que, em geral, está incluído no currículo de um curso de Psicologia, porém de forma dispersa, em disciplinas que normalmen- te são ligadas à área clínica.

Bem, se existe um conjunto de temas em Psicologia que constituem, por assim dizer, a "teoria" da psicologia hospitalar, é preciso lembrar que não só os enfoques teóricos destes temas podem ser diversos, mas também que os métodos e técnicas para a sua abordagem foram criados em situaçōes experimentais ou clínicas diferentes da situação hospitalar. Poderiam ser transferidos sem problemas para a nova situacão? Tomemos um exemplo que poderá ajudar a tornar mais clara a nossa preocupação: o método psicanalítico da livre associação, como método de acesso ao inconsciente, poderia ser utilizado na escuta de um paciente hospitalizado? Qual o sentido de seu emprego nesta situação? Caso utilizemos este método, o que fazer com o que ouvimos do paciente? Evidentemente nāo se trata ali de um processo de análise nos moldes em que esta foi concebida. Mas então como in tervir?

Pensamos que este exemplo ilustra um dos desafios da área emergente frente ao qual a sólida formação científico-metodológica, que salientamos anteriormente, é fundamental. É aí que se revela, talvez de forma mais nítida, a importância da pesquisa como processo de construção do conhecimento.

O estágio como lugar de iniciação a uma prática e, ao mesmo tempo, de reflexão teórica pode representar um espaço de criação, de construção de conhecimento, pelo desafio da situação nova. Mas não podemos esperar que os estágios realizem sozinhos a formação em uma área emergente. Mesmo tendo aí um papel importante, necessitam de uma formação mínima que os sustente.

Referências Bibliográficas
Bastos, A.V.B. \& Gomide, P.I.C. O psicólogo brasileiro: sua atuaçāo e formaçāo profissional, in Psicologia, Ciência e Profissão, Ano 9, n¹, 1989, p.615.

Conselho Federal de Psicologia. Atribuiçōes profissionais do psicólogo no Brasil, s.n.

Lo Bianco, A.C. O ponto de articulaçāo entre a graduação e a pós-graduação, in Bonfim, E.M. (org.)
Formaçōes em Psicologia: pós-graduação e gra duação. Belo Horizonte, ANPEPP/UFMG, 1996.

Mello, S. L. de . Currículo: quais mudanças ocorreram desde 1962? in Psicologia, Ciência e Profissão, Ano 9, n¹, 1989, p.16-18.

Weber, S. Currículo mínimo e o espaço da pesquisa na formaçāo do psicólogo, in Psicologia, Ciên cia e Profissão, Ano 5, 1985. 